\title{
Design and Implementation of an Online E-Commerce Website for Cars and Vehicles
}

\author{
Riyadh Mohsin Mohammed $^{1}$, Dr. Rafah S. Alhamdani ${ }^{2}$, Dr. Buthainah F. Abed ${ }^{3}$ \\ Higher Diploma Student, The Informatics Institute for Postgraduate Studies, University of Information Technology and \\ Communication, Baghdad, Iraq ${ }^{1}$ \\ University of Information and Communication Technology, Baghdad, Iraq ${ }^{2,3}$
}

\begin{abstract}
E-commerce is the utilization of electronic communications and digital information processing technology in business transactions between or among organizations, and between individuals and organizations. This aim of the project is to design and implementation the site that enables the customers to accessible site through the Internet using a personal computer to purchase any model of cars available at any time, which contributes to reduce the time, effort and cost. The PHP (Hypertext Preprocessor) language was used to build the website and the database build by using My SQL (structured Query Language), to provide a secure website.
\end{abstract}

Keywords: E-commerce, web site, cars, vehicles.

\section{INTRODUCTION}

E-commerce points to an extensive variety of online business activities for services and products. [1] Ecommerce is normally connected with selling and buying on the Internet, or doing any exchange including the exchange of ownership or rights to use services or goods through a computer-mediated network. [2] As well as Some companies have online client services accessible 24 hours. Hence, even after business hours, clients can ask questions, get necessary support or help, which has given convenience to consumers. [3] online shopping can be anywhere and anytime, it make consumers' life easier because they do not have to stuck in the traffic, look for parking spot, wait in checkout lines or be in crowd in store.[4]

Online trust is one of the most critical issues that affect the success or failure of online retailers.[5] Security is the challenge and the main problem for successful ecommerce implementation, as stated by many researchers. However, there is wide agreement between academic researchers that security is not only a technical challenge; rather it involves managerial, organizational and human dimensions to be more effective.[6] A Website consists of numberless pages that present information on any subject and linked together with hyperlinks, that is the essential part of the website. Website design tools are a combination of markup language and scripting languages. The languages that have been used in the design of the website are HTML, CSS, PHP and MYSQL. [7]

\section{BACKGROUND}

Electronic trade was present more than 40 years back and to this day .At the present time, it keeps on developing with new technologies, developments, and a great many business entering the online market every year since its commencement in the 1970's. [8] Electric business history goes back to the creation of the old idea of "sell and buy", electricity cables, PCs, modems and the internet. 1979, Michael Aldrich invented online shopping. In May 1984, 72 years of age Jane Snowball utilized groundbreaking new Gatehead council shopping and information service (SIS) to buy her weekly groceries from Tesco. [9] 1985, Nissan UK offers cars and account with credit checking to clients online from merchants.

The e-commerce industry kept on enhancing and delighted in a jump of success in 1994. Huge brands like pizza hut recorded its first deal through the internet. It was also around the same time that the first online bank opened. [10] The term electronic commerce was authored in the early 1990s when internet got to be marketed and clients started running to take part in the World Wide Web. Electronic commerce application was then quickly extended. Advancement of e-commerce; since 1995, many imaginative applications, running from direct online sales to E-learning knowledge had been developed. Nearly each association in the world has a website. In1999 the focus of E-commerce moved from B2C to B2B. [11]

\section{III.IMPLEMENTATION OF ONLINE E- COMMERCE WEBSITE}

This website has been designed to help customers to selling and buying online at anytime, anywhere reducing the cost and effort.

The languages that have been used in the design of the website are HTML, CSS, PHP and MYSQL. Some readymade scripts have included in the implementation process. In addition, the web design and development applications called 'Dreamweaver' has been used. In addition, the 
Vol. 4, Issue 2, February 2017

graphics editing programs called 'Photoshop' and 'Paint' has been utilizes.

The data gathering process includes gathering all the required information about online E-commerce for cars and vehicles, writing the required needs and preparing all necessary resources to build the website.

The website consist of many pages and the main interface, which includes logo Informatics Institute of Higher Studies, and which is accessible to several sub-pages that contain all basic information about cars and vehicles, type of cars, Guestbook and Contact Us page. All visitor access to this information, except to the control panel where it can be just to the site manager of the accessible through enter a user name and password.

\section{A. The Structure of the website Page}

The structure of the website must be chosen before considering the visuals. The information architecture utilized to describe the planing of a site's structure. There are two kinds of site structures that is that will eventually translate to the navigation menus: wide and deep. In wide navigation system, the main pages are all visible together and for small sites. An alternative method for organizing content is deep navigation, which simplifies the main navigation and groups related pages into categories. The deep navigation system is selected for Online E-commerce website for cars and vehicles, because it is the optimal solution for a large websites, drop-down menus and secondary navigation menu. So the general diagram is delineated in fig.1

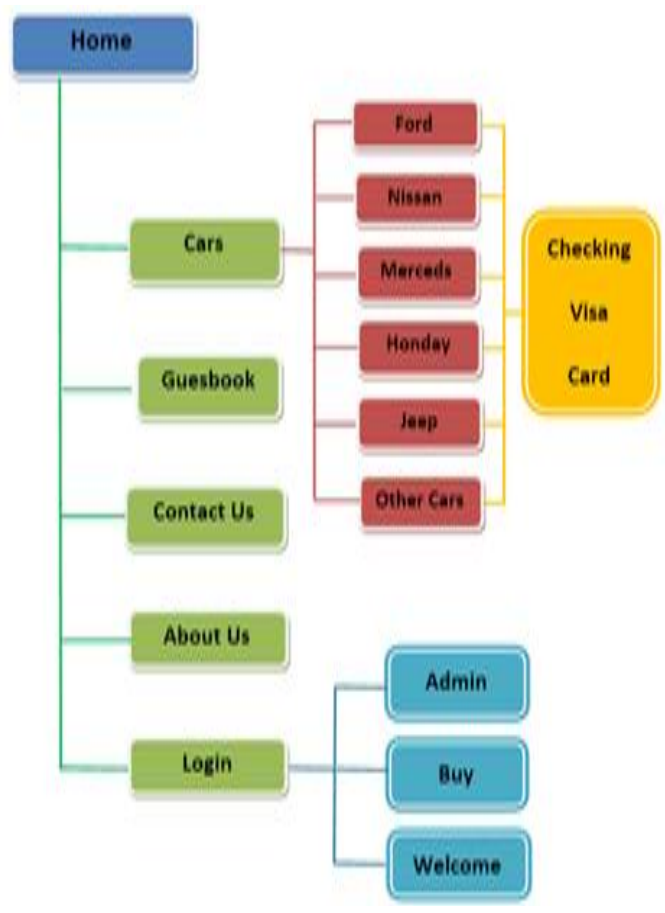

Fig.1. The General Diagram

B. Creating the data base

To designing a login system, buy page, guestbook page, the database has been worked for the website using PHP and MYSQL languages.
The database contain many tables, it must be a connection between the client and the server, in order to access the data base information, this process can be executed by using PHP statement:

Mysql_connecct() function. In addition to making a connection, the database must be closed automatically when the script ends. Closing operation can be executed by using the PHP statement:

Mysq1_close() function.

Database consist of one or more tables; each table consist of a number of many records, so the database created by using MYSQL languages that included statement:"CREATE DATABASE databasename".This statement can be done by using: mysql_query() function in PHP.

After creating the database, for example "car_db", now on or more tables can be built inside the database, this process is performed by using:MYSQL statement: "CREATE TABLE tablename".

car_db data base consist of three tables, the first tables for the requests of customers to cars buying, the second table for Remember visitor comments, the third table for admins website.

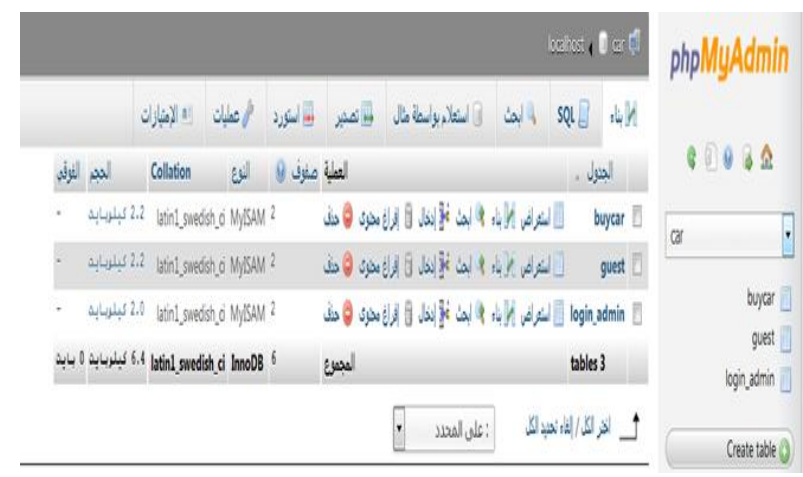

Fig.2. Making database in PHP My Admin on the local server

C. Technology Used in the website

* HTML: the page general format is designed in HTML language.

* CSS: the style of the website page is made utilizing CSS language.

* PHP: PHP: the back end that control the front end logic is applied by PHP language.

* JavaScript: the animations is made by JavaScript language.

* MYSQL: database made and control by the MYSQL language.

* Apache: website will be keep running over the Apache server.

* AdobeDreamweavercc2016: website composition application that alter and view the website pages.

D. Creating Interface page

The main interface of website is designed by utilizing HTML \& CSS codes. An interface includes logo Informatics Institute of Higher Studies and numerous pages that show information and images for online E- 


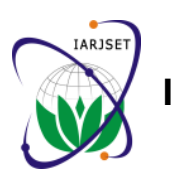

IARJSET

Vol. 4, Issue 2, February 2017

commerce website. All components of this interface are explained below:

The website header: consists of two sections Logo and the site nameas shown in Fig.3.

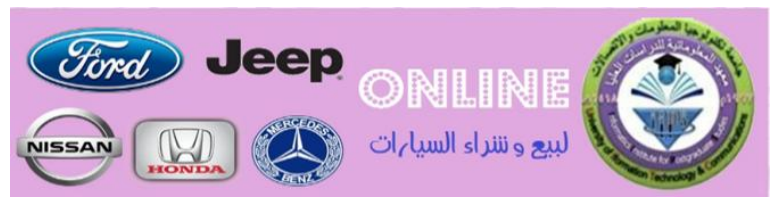

Fig. 3.The website header

The main bar: consist of Home page link, Cars page link, Guestbook page link, contact us page link, About page linkas shown in Fig.4.

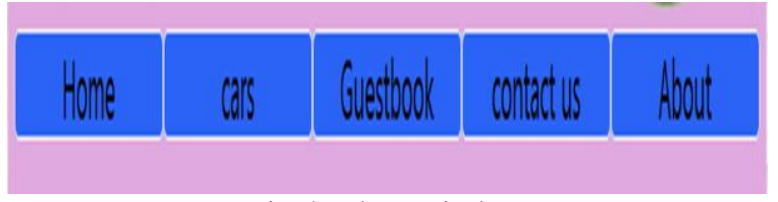

Fig.4. The main bar

The vertical side bar (right and left): consist of login page, links to other website and date and time, weather, facebook, youtube, and twitter.

Website body:the body differs according to the current page, below is the body of the first page as shown in Fig.5

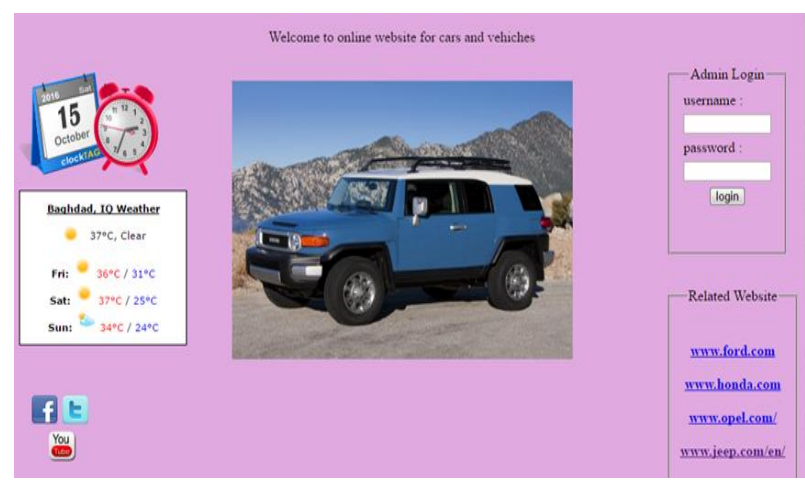

Fig.5. The website body

Website Footer: It is the last part of the website, include the copyright as shown in Fig. 6.

copyrightCall Rights reserved 2016
desgin by Riyadh Muhsin

Fig.6. The Website Footer

E. Development of the page

After building all files of the website and linking the pages together, know it is becoming a web application, these pages have been tested on a personal computer.The webpage created using HTML, CSS, PHP,javascript, and mysql.

1. Home Page : Welcome page gives brief summary of the portal of the University and can be accessed through it to all the other pages easily and clearly. It includes logo Institute of Informatics and a slide show of a set of images that show the nature of the website.

2. Cars page: This page contains a list of the kinds of private pictures available cars at the site and all the pictures are links include a range of features on the subpages, each sub-page containing the types of types of cars with their own pictures with the specifications of each type of car.

3. Guestbook Page: This page includes a form through which visitors can express their views and submit their proposals to develop the website.

4. Contact Us Page: This page includes a form through which to communicate with the site manager and also has a special location University of information technology and communication map in footer.

5. About Us Page: Page gives a brief summary of the website. Also has a special location University of information technology and communication map in footer. 6. Login Page: This page specific to site administrator, where they are through which access to the Control Panel.

7. Control Panel Page: Page Control Panel contains a set of pages through which enable the administrator access to the requests of customers for cars buying, as well as Add and Delete admin and also see visitor comments.

8. Admins Page: This page contains the user name and password for the administrator page, there is the possibility of adding a new page manager and the possibility of deletion.

9. Requests of Customers page: This page contains the requests of customers to cars buying and which page manager can control the comments that appear through the possibility to delete comments that are unrelated to the site completed.

10. Logout: This link allows the administrator page from the sign out and returns to home page.

\section{IV.CONCLUSION}

- Electronic Commerce applications support the interaction between various parties participating in a commerce transaction by means of the network, and the management of the data involved in the process. The essential objective of an Electronic Commerce site is to sell goods and services online.

- This project deals with developing Online an ecommerce website for cars and vehicles Sale. It provides the user with a catalog of various cars and vehicles available for buy in the website.

- The system is implemented using many web programming languages that are Hypertext Markup Language (HTML), PHP and My SQL languages.HTML is a language used to create Web pages. And second language in this project is PHP, it is a free, open source scripting language and is a server side language. And another language in my research is My SQL. My SQL is language for retrieving and manipulating data in a relational database (Data definition, Data manipulation, Data control). 
- The website is designed to allow customers to buying and selling in less effort and in any time and place even in night. This enables a Web page in addition to the Web site or be signed by the host on the Internet. And the implementation of this design by using Wamp Server.

\section{ACKNOWLEDGMENT}

I would like to express my deep gratitude to Dr. Buthainah Fahran Abed for her supervision during the period of the research, encouragement, comments and help. She opened the door for me to the world of research and has given me the necessary requirements to build my own identity as a researcher.

\section{REFERENCES}

[1] Rosen, A.: 'The E-commerce Question and Answer Book USA: American Management Association, 2000.

[2] Thomas, L.:Mesenbourg, Measuring Electronic Business: Definitions, Underlying Concepts, and Measurement Plans,, 2000.

[3] Hermes, N.: 'Fiscal decentralisation in developing countries, Review of medium_being_reviewed title_of_work_reviewed_in_ italics. De Economist, Vol. 148, No. 5:690-692, 2000.

[4] Childers, T.L., Carr, C.L., Peck, J. and Carson, S.: 'Hedonic and utilitarian motivations for online retail shopping behavior, Journal of Retailing, vol. 77, no. 4, pp.511-535, 2001.

[5] Prasad, C. and Aryasri, A Determinants of shopper behavior in etailing: An empirical analysis,, Paradigm, vol. 13, no. 1, pp.73-83, 2009.

[6] Sharma, A. and Yurcik ,W.: A study of e-filinr tax websites contrasting security techniques versus security perception, proceedings of the Tenth Americas conference on information system , New york , 2004.

[7] Deitel , H.M., Deitel, P.J.and Nieto,T.R.: 'Internet and World Wide Web How to program, , Second addition, Prentice Hall, 2002.

[8] Merchant, M.: The History of E-commerce: How did it all begin?, 2011.

[9] Lawson, J.: In the Beginning: The history behind e-commerce, 2014.

[10] Wee, W.: the history of E-commerce (Infographic), 2010.

[11] Lim, X.Y.: The history and evolution of e-commerce, 2008.

\section{BIOGRAPHIES}

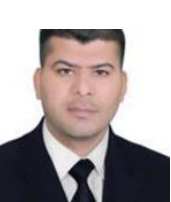

Riyadh Muhsin Mohammed, an Iraqi engineer, teacher of high school. Born in Thi Qar in 1985 and graduate from Al Mustansiriya University/ collage of engineer at computer \& software Engineering department at 2006 - 2007, I worked as a An employee of the local council in terms of the Gospels (2007 - 2010) and Teacher at the Ibn - Hayyan Secondary school of Boys (2008) and institute of teacher training $(2009-2012)$ and 2013 - present Teacher at Hussein high school .I have training course in Leadership Management in Najaf, visual basic , ICDL of computer, Auto CAD, primavera, all in Iraq and I have skill in Windows applications, HTML language, visual basic language , C++ language , c language, web design . in 2015 - 2016 I start study high diploma in Network Sites Technology from University of Information Technology \& Communications - Institute For Postgraduate Studies. 